\title{
Apontamentos sobre a Ord. L. 4 T. 47 pr.
}

Et certe cujusque rei potissima pars principium est.

De origine juris fr. 1.

Por muito tempo ficou ésta disposição legal sem nenhuma importancia prática, porque, quando a mulher não trazia dote, era ao marido rico facil convencionar a communhão de bens. Hoje, porém, em vista de haver casos em que a lei prohibe a communhão (Decr. n. ${ }^{\circ}$ I 8 I de 24 de Janeiro de I 890 art. 58), e estabelece o regimen dotal obrigatorio (art. 59 do cit. Dec.), é util examinar qual o verdadeiro sentido, e qual a extensão deste preceito legal. Mas, contra o que acabamos de dizer surge logo uma objecção: qual a importancia da Ord. L. $4 \mathrm{~T} 47$, cópia da Manoelina L. 4 T 93 ult. (Cabedo n. ${ }^{\circ}$ I Val. Cons. 3 n. $^{\circ}$ 5), si já então dominava o regimen da communhão legal como permittido em todos os casos? Responder a essa objecção será dar a razão por que foi collocado nos codigos Manoelino e Philippino este preceito de que não excedam as arrhas a terca parte do dote. Várias pódem ser as explicações. 
A primeira é que, si a lei permittia a communhão de bens em quaesquer casos (Clovis Dir. da Fam. $\ 36$ pg. 229), não a toleravam os costumes em casamentos de pessôas nobres (Gama, dec. 370 n. ${ }^{\circ}$ I.) Justamente para éstas é que naturalmente foram escriptas as leis Manoelina (Ord. L. $4 \mathrm{~T} 9$ \$ult.) e Philippina (Ord. L. $4 \mathrm{~T} 47$ pr.), pois é sabido que muito occupou a attenção dos legisladores portuguezes cohibir o fausto nos casamentos de pessoas nobres. Disso dão testemunho as 2 leis de 17 de Agosto de I 76 I, ás quaes se refere a de I 7 de Julho de 1778 , inspirada do mesmo desejo de cohibir gastos excessivos, como se vê nas expressões "visto que desta Providencia não resulta a conveniencia que nesta Lei se considerou" (Coll. Delgado v. 3 pg. I 7I), e a lei de I4 de Agosto de I645, que se acha no Ep. 2 pgs. 45 e 46 de Paiva e Pona, e no T. 4 pgs. I08 e io9 da Collecção de D. João V Assim a prescripção da Ord. l. 4 T 47 pr. tinha em vista -segundo este primeiro modo de explicar sua razâo de ser-os casamentos das pessoas nobres, que julgavam a communhão um regimen de plebeus.

A segunda explicação que nos occorre é de ter sido mantida pela vis inertice, como preceito peculiar da morgengabe, que era provavelmente dum terço, como o eram os acquestos, segundo Roth citado por Clovis (Dir. da Fam. pg. 225). E' algum tanto imaginosa, confessamos, ésta segunda explicação, mas nem por isto inacceitavel num instituto, qual o das arrhas, em que tudo são duvidas, ignorando os mestres si o devem filiar á donatio propter nuptias, si á morgengabe (Arouca, All. 7I n. ${ }^{\circ}$ 8, Cabedo P I dec. I 77 n. $^{\circ}$ I, Val. Cons 2 pr. e n. $\left.{ }^{\circ}{ }_{1} 3\right)$.

Força é tambem confessar que mais nos inclinamos para os que consideram as arrhas como producto 
da evolução das donationes propter nuptias, (GUERREIRo) -De div. T 2 L 7 c. 7 n. ${ }^{\circ}$ 5. Sanchez L. 6 D. I n. ${ }^{\text {Ds }}$ I e 8 para os quaes surge uma terceira explicação da origem da Ord. L. 4 T. 47 pr.)

Sabemos que as donationes propter nuptias, de cuja construç̧ão juridica não podemos ter hoje perfeita notícia, segundo Maynz (v. $3 \rrbracket 316$, Mackeldey, $\$ 563$ n. ${ }^{\circ} 3$, Mühlenbruch, $\left.\ 539\right)$, foram reguladas sob a influencia das idéas orientaes (Cuq. v. 2 pg. 809), e provavelmente foram restringidas, a principio, ao valor da metade do dote por Constantino (Cuq. v. $2 .^{\circ} \mathrm{pg} .809$ ), e mais tarde á totalidade (Nov. $97 \mathrm{c.}$ I), donde a justificação dos nomes de contradote e antipherna, que tiveram no Direito (Mackeldey $\mathbb{S} 5_{6}$, Van Wetter \$554). E' bem de crer que o limite das donationes propter nuptias a um certo maximo; não tivesse só por intuito contrabalançar o dote (Nov. 97 c. I), mas tambem cohibir a accumulação de grandes capitaes nas mãos das mulheres, limitação que sempre foi grata aos romanos, como o mostraram na lei Voconia e em outras, e no direito dos prudentes (Maynz, \I3).

Parece que essa tendencia romana se accentuou sob o influxo das idéas orientaes (Cuq. v. 2 pgs. 809 e 8ro). Como fosse a communhão de bens por força do casamento desconhecida dos romanos (Mackeldey $§ 55 \mathrm{I})$, é explicavel a existencia da restriç̧ão da donatio propter nuptias ao valor do dóte. E' de crer que fosse ésta donatio propter nuptias que passasse para o direito lusitano e para o hespanhol, com sua fórma romana, mas com uma modificação do quantum (Cabedo P I dec. I 77 n. ${ }^{\circ}$ I, Arouca All. 7 I n. $0^{\circ}$ ); e, encontrando o novo instituto da .communhão, se atrophiasse ao ponto de ser considerada como quasi um fossil por $\mathrm{T}$ de Freitas (Cons. art. 89 n. ${ }^{\mathrm{a}}$ I 9 ) 
e por Clovis (Dir. da Fam. \55 p. 319). Com effeito o texto legal, de que estamos a occupar-nos, é hoje conhecido de limitado numero de praticos.

$$
* * *
$$

Vejamos qual a exacta noção das arrhas, de que tracta a lei que faz objecto da nossa attenção. Diz T de Loureiro, paraphraseando Mello Freire : "Entre nós chamam-se arrhas a quantia certa que no contracto dotal o esposo dá ou promette dar á esposa sem distinç̧ão alguma entre solteira e viuva». (Inst. I I $68-4 \cdot{ }^{\mathrm{a}}$ ed.). No mesmo sentido B. Carneiro (\$ I 52 n. ${ }^{\circ}$ I) e Mello (L. 2 T. 9 29).

Mas outros na definição põem em evidencia o caracter de pacto successorio das arrhas. Assim Lafayette diz: "Denominam-se arrhas a pensão, ou ou cousa certa e determinada, que no contracto dotal o marido promiette á mulher PARA O CASO DELLA LHE Sobreviver» (Dir. de Fam. \92). Do mesmo modo se exprimem C. da Rocha (Inst. $\ 282$ ) e Clovis (Dir. de Fam. \55).

Esta definição faz resaltar o facto de se unirem as arrhas ao dote para que do todo usufrúa o marido (Lafayette $\$ 95$ ). Outro tanto succede, parece, com a doação propter nuptias (Mühlenbruch Doct. \539 n. ${ }^{\circ}$ 2), mas não julgamos isto livre de contestação, em vista da lettra da Nov. 97 c. I, uma das taes concebidas em termos mais prolixos do que claros "verbosa magis quam dilucida oratione", segundo Mühlenbruch. Tambem sobre qual dos conjuges seja o dono do objecto doado propter nuptias não ha accordo entre os escriptores (Mühlenbruch Doct. \& 539 n. $^{\circ}$ I I ). Outras questões gravissimas se suscitam sobre pontos importantes da noção das donationes propter nuptias (Haimberger $\ 533 \mathrm{n} .^{\circ} 7$, Mühlenbruch 
nota á rubrica do $\ 339$ ), e isto mostra que de pouco auxilio deve ser o direito romano, como subsidiario do nosso, para estabelecermos o verdadeiro caracter das arrhas.

C. da Rocha diz que no sentido lato a expressão arrhas comprehende os apanagios, ou rendimentos annuaes que a mulher durante a viuvez tem direito a receber da casa de seu finado marido. Lafayette julga que as leis que regiam os apanagios deixaram de vigorar, porque eram fundadas na distincção entre nobres e plebeos $(\$ 96)$. Com effeito a lei de i 7 de Agosto de I76I no $\$ 7$ se refere a pessoas nobres, mas porque era uma verdadeira lei sumptuaria, destinada a cohibir o luxo e fausto nos casamentos dos fidalgos. O que porém dispõe acerca da subsistencia decente das viuvas que não são meeiras, parece applicavel ainda hoje a todos, sem-distincção entre plebeos e fidalgos. A leitura do preambulo e do $\int \mathrm{I}^{\circ} \mathrm{da}$ lei de 4 de Fevereiro de 1765 mais nos confirma nesta opinião de que a preocupação do legislador era prover á decente subsistencia da viuva, em proporção com o seu estado, dando-lhe alimentos em quanto não passasse a segundas nupcias.

Além dos apanagios, que, segunclo C. da Rocha, estão comprehendidos no sentido amplo da expressão arrhas, ha o dotalicio que, na opinião de Lafayette, nunca esteve em uso, nem em Portugal, nem no Brasil ( $₫ 96)$. Era uma instituição germanica, e consistia na promessa que o esposo fazia á esposa de certos bens para sua decente subsistencia na viuvez (Lafayette $\ 96$ ).

Dominando a evolução das arrhas, com grande largueza de vistas, pretende Clovis que se deo uma translação de sentido do vocabulo arrhas, passando a significar em época mais recente o que o esposo 
dava á esposa propter nuptias, quando antes significava a garantia ou segurança dos esponsaes.

$\mathrm{Na}$ peninsula iberica havendo o instituto do doario, que Clovis previne não ser o morgengabe (germen da communhão) (I) passou a ter o nome de arrhas, que vinha de Roma, ou antes do Oriente, por intermedio do direito romano. Eis como para Clovis as nossas arrhas e camera cerrada (2) não passam da junçãa das idéas germanicas com as romanas, havendo porém no seu entender verdadeiramente uma instituição germanica embora com um nome oriental.

O mais verosimil para mim é que o nosso instituto das arrhas proveio da doação propter nupiias romana, e que se modificou sob a influencia das novas idéas que surgiam no campo do Direito romano.

A prova disto é o facto de serem ellas proporcionadas ao dóte, instituto genuinamente romano, pois $\in \mathrm{m}$ outros povos era o dóte uma instituição amorpha, ou ainda não organizada (Voetio L. $23 \mathrm{~T} 3$ I). Não é forte a objecção tirada das differenças entre as arrhas $\mathrm{e}$ as donationes propter nupcias. (Val. Cons. 2 n. ${ }^{\circ} \mathrm{s}$ 6 e sgs.). Explicam-se essas differenças pela evolução por que passam os institutos juridicos, mórmente quando sobre elles exercem influencia institutos similares já organizados noutros povos. Bem diz Strykio que com o tempo, sob o effeito de várias circumstancias; mudaraın-se a indole e a natureza do instituto romano denominado donatio propter nuptias, e aponta como lima dessas modificações não mais dever a doação ser

(1) No L. 23 T. 3 n. 13 diz Strykio que Brunnemann considera desusada a donatio propter nuptias, e substituida entre pessoas nobres pela morgengabe, "quæ tamen donatio propter nuptias, quœ jure romano debetur, proprie non est."

(2) Na nota a esta expressão da Ord L. 4 T. 47 (camera cerrada) traz C. Mendes interessantissimas informações acerca do sentido que the deve ser dado. Algumas interpretações, força é dizer, são cerebrinas demais 
igual ao dóte. Julgava Strykio desusada a Authentica que prescreve a egualdade entre o dóte e a donatio propter nuptias (Strykius Us. L. 23 T. 3 n. $0^{\text {os }}$ i 4 e 15 ). E' ésta tambem a opinião de Brunnemann, citado pelo mesmo Strykio (n. ${ }^{\circ}$ I 3 ). Valasco, depois de enumerar os pontos em que se assemelham, e os em que differem as arrhas e as donationes propter nuptias, diz que este instituto das donationes foi por aquelle substituido na Hespanha (Cons. 2 n. I 3 ).

$\mathrm{Si}$ examinarmos as modalidades por que tem passado desde os mais remotos tempos, o patrimonio da familia, encontraremos na sua phase primitiva alguma uniformidade $(\mathrm{H}$. Post. Jur. Ethn. v. $2 \rrbracket 3 \mathrm{I}$ n. I) ; mas logo, com o desenvolvimento do Direito, e com o melhoramento das condições da mulheras mais accentuadas divergencias surgem neste assumpto. Eis as proprias palavras de Post a este respeito: "Nas particularidades temos de novo todos as possiveis divergencias, pois este dominio juridico é dos que tomam os mais variados aspectos. Só em certas tendencias pertence á evolução universal do direito, tendencias que devemos agora brevemente assignalar. Todas as particularidades pertencem á historia especial do direito"

Logo em seguida procura Post enfeixar em formulas geraes a genese e o desenvolvimento do peculio familiar, e menciona a variedade infinita de modalidades que assumem as relações patrimoniaes na familia. Acerca do modo de constituição do peculio da mulher, que Post julga formado, já pelo preço da compra da mulher, já pelo presente da manhan, observa o grande mestre: "Sobre taes bens da mulher ambos os conjuges podem ter direitos, que nas minucias variam depois profundamente entre os diversos povos, e em cada especie de bens. Os direitos do marido 
sobre taes bens mostram as mais profundas differenças» (Jur Ethn. v. $2 \$ 3 \mathrm{I}$ n. 2).

Em nota, dá-nos noticia do stridhana indu, que corresponde ás nossas arrhas, á donatio propter nuptias dos romanos e ás outras instituições nascidas da evolução da primitiva compra da mulher ( $n .^{a} 5$ ).

Do exposto concluimos que as nossas arrhas não passam duma evolução da donatio propter nuptias dos romanos, que por sua vez é filha da compra da mulher, e representa uma das muitas modalidades de tal instituição primitiva. $O$ instituto romano soffreo na peninsula iberica a influencia da variante do direito germanico.

$$
*^{*} *
$$

Em cada povo pois, segundo as necessidades locaes e de momento, tomam as instituições caracteres particulares, e, como nota Post, variando muitissimo nos diversos povos a condição da mulher, variam consequentemente muito os direitos patrimoniaes da familia. Para eloquente prova dessa diversidade de condições da mulher, ainda em povos de civilização relativamente elevada, basta reproduzir o que refere o mesmo Post, acompanhando a Lehr: "Na common law ingleza a mulher casada era ainda em pontos essenciaes totalmente privada de direitos.

Não podia prestar testemunho, nem concluir contractos, nem comparecer em juizo.

Os delictos, que commettia diante do marido eram a este attribuidos, seu patrimonio movel, e os acquestos por ella feitos eram devolvidos ao marido.

Dos bens immoveis da mulher elle tinha ao menos a administração e o uso» (Post. Jur. Eth. $\ 3$ I n. ${ }^{\circ} 2$ n. ${ }^{\text {a }}$ 6, pag. I I 2 ). 
$\mathrm{O}$ que nos cumpre pois, na interpretação e applicação da lei patria, é investigar qual o espirito que dominava na legislação sobre o patrimonio da familia. Ora parece-nos que a condição da mulher nas leis do Reino era muito semelhante á da ingleza, descripta por Lehr (Mello Fereire Inst. L. 2 T 7, Lobão Notas ao $\mathbb{I}$ I e 2, Ord. L. 5 T $36 \mathbb{I}$ ). Nas fontes indicadas por Lobão (loc. cit.)., por Borges Carneiro ( $\mathbb{I}$ I 7 ) e por outros se vê que era, diga-se de passagem, quasi geral em toda a Europa essa posição inferior, ou de proteç̧ão, em que se achava a mulher. Podemos dizer que era equiparada ao menor, gozando de beneficios analogos aos deste, e sujeita a analogas restricções de capacidade. Si, em Roma, onde tão grande importancia social, quão restricto valor juridico, teve a mulher (Mommsen Man. das Ant. V I 4 c 2,) procurou-se cohibir a concentração das fortunas em mãos femininas (Bonjean Inst. v. I pag. 685), é de suppôr que a mesma preoccupação continuasse nos legisladores dos seculos posteriores, preoccupação que se revela pelas restriç̧ões da capacidade juridica da mulher, que se mostram nas lejs até epoca recentissima.

E' conviç̧ão nossa que a Ord. L. $4 \mathrm{~T}_{8} 47 \mathrm{pr}$. teve como motivo evitar grandes riquezas em mãos de mulheres. Estas ideas economicas tanto em relação á mulher como em geral (I) cohibindo o luxo, se manifestam até nas leis de I7 de Agosto de I76I, alias suspensas ou modificadas em parte pela de i 7 de Junho de I 775, dominada pela mesma orientação de protecção á fortuna publica. Manifestam-se ainda essas idéas na lei de I 4 de Agosto de i 645, que se acha transcripta em Paiva e Pona, Epilogo 2. ${ }^{\circ}$ Fgs. 45 e 46 e na collecção de D. João V v. 4 pgs. IO8

(1) Alvará de 2 de Abril de 1762, dec. da mesma data etc. 
e I09. Era opinião dominante que a opulencia da mulher constitue importante factor para sua corrupção, particularmente pela sua tendencia para o luxo. (Bonjean Inst. v. i p. 685 Mommsen Man das Ant. v I 4 p. 74 ).

$$
*^{*} *
$$

Esses elementos nos habilitam a melhor entender a Ord. L. 4 T 47 pr. $E^{\prime}$ interessante que sempre se tenha procurado modificar ou fraudar o sentido desse preceito legal, a pretexto de o interpretar. Nos paizes de direito commum não houve necessidade desse artificio : como o instituto romano não estava de accordo com as idéas da epocha, e não era apoiado por lei local, perdeo a força juridica, que lhe vinha do costume (Dernburg. Pand. I e Sav. I 8 ).

No Direito Patrio porém temos lei expressa, o que força os jcts. a sophismar o texto legal.

Trigo de L Loureiro diz que é certo que pela Ord. L. 4 T 47 pr. "não ha arrhas onde não ha dote», mas accrescenta que, "pela Ord. L. 4 T 46 pr. vrs. salvo quando, a doutrina contrária é mais razoavel, mais segura e mais justa," e "assim bem póde o esposo excluir a communhão promettendo á esposa arrhas, que não excedem á sua terça» (\$ I68).

Pelas palavras de Loureiro é de inferir que elle julga contraditorias as duas Ordenações. Parece-nos porem claro que não ha tal contradiç̧ão.

A Ord. L. 4 T 46 permitte ao marido excluir a communhão, e fazer com a mulher qulquer accordo acerca dos bens do casal, mas, está visto, com exclusão dos pactos contrários á lettra legal, como é o de arrhas sem dóte, prohibido pela Ord. L. 4 T 47 pr.. Nem se póde dizer que tenha havido descuido, pois já o assumpto fôra objecto de discussão antes da reforma 
philippina (Cabedo Dec. I 77 n. ${ }^{\circ}$ I, Vall. Cons. 4 n. ${ }^{\text {os }} 6$ e 7$)$.

Outro jct. patrio que tracta de fraudar a Ord. L. 4 T 47 pr. é o grande $\mathrm{T}$ de Freitas. Reproduzirei textualmente suas palavras:

"Actualmente ésta prohibição de exceder a promessa ou doação a terça parte do dote, não merece attenção, não é observada. Todavia como a Ord. L. 4 T 47 está em vigor, releva ponderar que ella só procede quando a mulher traz dote e o marido lhe promette ou dôa alguma cousa; não assim quando a mulher é dotada pelo marido, o que acontece todos os dias. Não se repute ésta constituição de dote pelo marido como illegal, ainda que a mulher tenha alguma cousa de seu» (Nota ig ao art. 89 da Cons.)

Assim, em resumo, diz:-que a Ordenação não é observada,- que está em vigor,-e que não se applica á mulher indotada, ainda quando não seja pobre. Com effeito podia-se, ao tempo em que escreveu $\mathrm{T}$ de Freitas, evitar a applicação da Ord. L. 4 T 47 pr., acceitando o regimen da communhão, admittido sempre, salva, segundo Pegas (Laf Dir. de Fam. \64 n. ${ }^{a}$ I da pg. I 26), a hypothese do casamento da viuva quinquagenaria com filhos, que absolutamente não nos interessa, pois cogitamos justamente do caso de mulher que não traz dote, e portanto que não tem bens. Sendo possivel sempre a adopção do regimen da communhão, deveria se considerar de nenhum alcance prático a Ord. L. 4 $\mathrm{T} 47$ pr., ao tempo em que escreveu $\mathrm{T}$ de Freitas, quando nenhum motivo legal, nem de preconceito social havia para se deixar de acceitar a regimen da communhão. Affirmar porém que a Ord. L. $4 \mathrm{~T} 47$ pr. se applica á mulher que traz dote, e não á indo- 
tada é doutrina que não póde admittir, embora tenha por si muitos seculos. (Cabedo Dec. I 77 n. ${ }^{\circ} 3$ ). Dando noticia deste modo de interpretar a Manoelina do L. 4 T 9 \ult. diz Cabedo: "Unde si nihil ex uxoris parte in dotem datum fuerit, nihil ei promitti nomine arrharum posse, sanior opinio est, et in senatu nostro approbata: aliter melioris conditionis esset mulier indotata quam dotata».

Relatando as diversas questões juridicas suscitadas em certa causa importantissima, escreveu Gama: - Dubitatio fuit an de arrhis promissis sit solum solvendœ pars quœ prorata tangit dotem receptam? Et affirmavi id juri consentaneum esse ut sola prœdicta pars solvatur, adeo quod si nulla pars dotis promissa a marito recepta sit, nulla pars arrharum ab eo solvenda erit».

Desta especie, mencionada por Gama, e relativa a uma dotis datio, podemos ampliar o aresto para o caso da dotis promissio, firmando o principio de que onde não ha dote (dado ou promettido) não ha arrhas.

Arouca (All. $7 \mathrm{r}$ n. ${ }^{\circ}$ I) menciona ainda um modo de illudir a Ord. L. $4 \mathrm{~T} 47$ pr. sustentado por Sanchez e Gabriel Pereira, qual o de dar as arrhas como doação remuneratoria, perdendo assim o caracter de liberalidade que lhes é peculiar, e escapando ao rigor do preceito do cit. pr. da Ord. L. 4 T 47

Para se ver a agudeza Sanchez e Pereira, rivaes de qualquer sophista grego, e que por vezes se perderam em filigranas em moda na sua epoca, é bom transcrever as proprias palavras do luzeiro portuguez.

Diz a rubrica: "De dote ab sponso consanguineo sponsœ pauperi promisso juxta Summi Pontificis dispensationem $\gg$. Continúa o jct. patrio (Ar. All. 7 I n. ${ }^{\circ}$ I) : 
"Dubitavi in causa non parvi momenti, utrum verum esset quod scribit Sanchez et Gabriel Pereira, non esse scilicet donationem, sed ex causa onerosa, dotem, quœ ab sponso in tempus matrimonii, vel a viro uxori pauperi promittitur eo caso, cum Pontifex cum illis ea lege dispensaverit, ut vir uxorem pauperem dotaret; parificantes dotem et donationem hanc cum illa quam rusticus, vel senex sponsæ virgini, vel uxori nobili facit remunerandœ virginitatis et nobilitatiscausa» (4). E' uma subversão de todos os principios juridicos.

Arouca impugna tal doutrina com logica esmagadora. Eis como se exprime: "Primo Ord. L. 4 T 47 quœ sicut arrharum donationem annullat et invalidat in residuo, quod maritus promisit ultra tertiam partem dotis, ita invalidare videtur et in totum prohibere si mulier, prout in casu nostro, nihil dotis secum attulit; nam appellatione residui totum continetur» (n. ${ }^{\text {s }} 6$ e 7$)$.

No mesmo sentido que Arouca se manifesta Mello Freire: "Hæ autem promissio, datiove ut valeat neque quidquam arrarhum nomine ultra tertiam muliebris dotis partem dari, sponsi licet diversœ atatis, conditionis et ordinis sint; hanc enim distinctionem non solum non agnoscit, sed expresse improbat eadem Ordinatio verbis: Mandamos que pessoa alguma .» (L. 2 T 9 \ 29).

Eis o que vale o sophisma de Sanchez e Gabriel Pereira na especie de serem as arrhas dadas a uma virgem por um velho, ou a uma mulher nobre por um plebeo.

Ha ainda o recurso da dispensa de que nós dá noticía Lobão, (Notas a Mello-L. 2 T 9 \ 29 n. 8

(4) Valasco apoia a Suarez, que sustenta que nesta hypothese pódem se: constituidas na arrhas constancia do matrimonio (Cons. 4 ns 5 . e seguintes). 
v. 2 p. 525), dispensa que facilmente se concedia, segundo Lobão, e que não se concedia, segundo $\mathrm{T}$ de Freitas (Notas a Mello v. 2 p. 525 n. 8, Cons. n. I9 ao art. 89).

Hoje, nem ao nosso Congresso compete dispensar da lei, e portanto a evasiva perde a importancia.

$$
* *
$$

Cumpre esclarecer agora dous pontos: um é qual a dispensa que o Papa dava desta Ordenação, e outra si no direito patrio continúa a prohibição absoluta de dotar o marido á mulher. Trataremos de ambas as questões conjuntamente, em vista da affinidade que ha entre ellas, sendo a primeira comprehendida na segunda. Pegas claramente diz (For. 3 c. 36 n. ${ }^{\circ}$ I 7 ): "Est contra Jus Civile et contra Jus Gentium quod maritus dotet uxorem."

De facto, si o dote é destinado a habilitar o marido a sustentar, com os seus fructos, os encargos do matrimonio, é logico que seja por outrem dado, ou melhor por outrem fornecido á mulher para que ésta o dê ao marido. Por isto Pegas (5) dá caracter de simples doação remuneratoria á que o marido faz á esposa «in præmium pudicitiœ, juventutis et eximiœ qualitatis» (n. I 8). Sanchez porém considera dote (L. 6 D. $7 \mathrm{n.}^{\circ} 3$ ) em primeiro logar a doação "quando vir exceditur ab uxore, nobilitate vel œtate: ut si ignobilis aut senex ducat nobilem aut juvenculam. Menciona Sanchez em $2 .^{\circ}$ logar o caso do crime contra a honra da

(5) Repetimos porém: quer com o nome de dote, dado por Sanchez, quer com o de doação remuneratoria dada por Prgas, são inadmissiveis as arrhas dadas ou promettidas á mulher que não traz dote, por mais peregrina que seja a esposa, e por menos dotes naturaes que tenha o marido. 
mulher antes do casamento. Em $3{ }^{\circ}$ logar refere a dispensa pontificia nos seguintes termos: "quando Pontifex dispensaret cum duobus consaguineis, ea lege, ut in uxorem pauperem dotaret: valebit enim dotis constitutio. Quia non est donatio, sed ex causa onerosa datur, ut Pontifex dispenset.» Refere em $4 .^{\circ}$ logar o costume, e em $5 .^{\circ}$ o caso da necessidade da paz domestica. Hoje o $3 \cdot{ }^{\circ}$ caso não tem nenhuma importancia no fôro secular, e, quanto aos demais, só o segundo póde merecer attenção, porque não deixa de offerecer difficuldade a applicação do art. 276 do Cod. Penal, nos casos em que é prohibida a communhão).

Julgo que, em tal hypothese, embora cesse a applicação da pena, não desapparece a obrigaçâo de dotar. Mas quando a lei penal falla em dotar a offendida, evidentemente emprega a expressão no sentido de lato e vulgar ( $\mathrm{T}$ de Loureiro-Inst. \$ r 48), e não no restricto de bens destinados a occorrer por seus rendimentos aos encargos matrimoniaes. Segundo as circumstancias, poderá a mulher que recebeu taes bens dar-lhe o caracter de paraphernaes, recepticios ou dotaes, como lhe convier.

$\mathrm{Si}$ o pedido do dóte a que se refere o art. 276 do Cod. Penal fôr feito na constancia do casamento, claro me parece que esses bens terão o caracter de recepticios.

Em conclusão pois: o marido nunca pode dotar a mulher, contra o que ensina Sanchez.

Força é pois reconhecer que qualquer doação feita pelo marido á esposa que não trouxe dote é nulla nos termos rigorosos da Ord. L. 4 T 47 pr., e que são sem fundamento juridico quantas evasivas imaginaram os jurisconsultos patrios. Faz ésta Ordenação parte do conjuncto de medidas adoptadas pela legis- 
lação para não se darem os casamentos filhos unicamente do interesse pecuniario.

Pondo termo a éstas notas, convem que façamos sentir que nos abstivemos de qualquer crítica das providencias adoptadas pela nossa lei para conseguir a repressão desta repugnante exploração do amor.

Diremos porém que, comquanto não sejam condemnaveis todas as medidas adoptadas pela lei que nos rege, ha entretanto muito a fazer para conseguir construir em preceitos legislativos o muito que a doutrina já firmou.

Dr. Jỗo Arruda. 